Rapid Reviews COVID-19

\title{
Reviews of "The effect of eviction moratoriums on the transmission of SARS- CoV-2"
}

Srini Venkatramanan ${ }^{1}$

${ }^{1}$ University of Virginia, Biocomplexity Institute, USA

Published on: Feb 22, 2021

License: Creative Commons Attribution 4.0 International License (CC-BY 4.0). 
To read the original manuscript, click the link above.

Summary of Reviews: Reviewers find this a timely paper that makes a case for the epidemiological importance of maintaining eviction moratoriums, but may overstate its conclusions given the simplicity of the model.

Reviewer 1 |

\section{Reviewer 2 (Srini Venkatramanan) | प्र००}

\section{RR:C19 Strength of Evidence Scale Key.}

प्रमप्र = Misleading

प्र००० = Not Informative

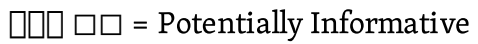

प्र०प्र = Reliable

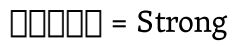

To read the reviews, click the links below. 